\title{
Religious Boundary Work and Class Representations - A Theoretical Framework to Study Middle Class Pentecostalism
}

This chapter will sketch the theoretical framework of the study. The theoretical framework aims to describe and analyze the specific case of Argentinean middle class Pentecostalism. Hence, the theoretical approach outlined here is primarily designed as a theory of Argentinean middle class Pentecostalism. For this reason, there will be a theoretical - and empirical - focus on the middle class.

Since the main objective of the theoretical approach is to describe and analyze a specific empirical phenomenon, sociological theory will be applied as a toolkit that helps us to grasp, describe, and understand the given social phenomenon. ${ }^{1}$ When investigating a particular social phenomenon, specific theoretical instruments of this toolkit become relevant and some tools must be adapted to the empirical conditions. Following this logic, the theoretical framework presented here developed in dialogue with the empirical results.

A theory of middle class Pentecostalism in Argentina must meet certain conditions. For studying the presence of the middle class in a predominantly lower class religious movement one needs a theoretical approach that conceptualizes the relationship between class and religion, but, at the same time, makes allowances for non-conformance with class standards. In other words, the approach must bring together the contradictory tendencies of middle class Pentecostals: the non-conformance with and the adaptation to class order. Further, the approach must tackle the social tensions that arise from the nonconformance of middle class Pentecostals and how they deal with these tensions.

The most suitable approach for the study of the relationship between class and different types of practice is Pierre Bourdieu's sociology. His sociology lends itself not only to the study of social class but also for the study of religion as was shown, for instance, by scholars like Terry Rey, Heinrich Schäfer and Leif Seibert. ${ }^{2}$ For studying the specific case of Argentinean

1 See for Bourdieu's sociology as a toolkit, Bourdieu and Wacquant 1992: 160.

2 See Rey 2005; 2007; Schäfer 2002; 2004; 2005; 2011; Seibert 2010.

(C) JENS KOEHRSEN, 2016 | DOI 10.1163/9789004310148_003

This is an open access chapter distributed under the terms of the Creative Commons Attribution-

Noncommercial 3.o Unported (CC-BY-NC 3.0) License. 
Pentecostalism, the theoretical framework of Bourdieu's sociology is applied in a specific way. Essentially, adding the concept of symbolic boundary work and the notion of middle class representations extends the theoretical framework.

The concept of symbolic boundary work emphasizes the everyday practice of individuals to draw symbolic boundaries (distinctions) between themselves and others. These boundaries can serve as markers of class belonging. For instance, Argentinean middle class individuals may portray themselves as educated and well-mannered in opposition to the Argentinean lower class, perceived as lacking education and manners. The boundaries that middle class individuals tend to draw in opposition to other classes can accumulate over time into a system of established middle class boundaries. This study refers to these established boundaries as middle class representations. Middle class representations are institutionalized symbolic boundaries that form an idealtypical imaginary of the middle class. This middle class imaginary assumes a rule-like character and frames the everyday boundary work of middle class individuals by constituting a pool of established class distinctions. These class distinctions define what type of behavior is regarded as appropriate for middle class individuals. Nevertheless, middle class actors may deviate from these standards of appropriate behavior by dedicating themselves to practices that will probably not be perceived as appropriate by middle class peers. The inappropriate behavior may lead to tensions. In these cases, boundary work enables actors to negotiate the appropriateness of their practice by drawing symbolic boundaries in opposition to the characteristics of the practice perceived as inappropriate.

The choice of these two conceptual extensions is related to the research topic and the empirical findings of this study. The two conceptual extensions lend themselves to the research focus on Argentinean middle class Pentecostals, since they stress two aspects central to understanding middle class Pentecostalism in Argentina: (1) the partial non-conformance with class-related standards of appropriate behavior and (2) the negotiation of this non-conformance.

In order to develop the general theoretical framework of this study, the theory section continues with a short introduction into the relevant pieces of Bourdieu's sociology. Such a brief introduction can evidently not reflect the complexity of Bourdieu's sociology but tackles only the elements that are necessary for the proposed analysis of middle class Pentecostalism in Argentina. After this introduction, the concepts of boundary work and middle class representations will be described and embedded into this framework. 


\section{Bourdieu's Sociology as a General Framework for Grasping Class in Religion}

This study employs Bourdieu's sociology as a general theoretical framework to explore Argentinean middle class Pentecostalism. ${ }^{3}$ Adapting Bourdieu's sociology to the case of Argentinean middle class Pentecostalism, the study uses an approach to Bourdieu that may be perceived as unorthodox. This approach aims to describe the non-conformance with and negotiation of class order and distances itself, therefore, from interpretations that understand Bourdieu's sociology in a rather deterministic way.

The theoretical framework is particularly based on Bourdieu's seminal work La Distinction: Critique sociale du jugement. ${ }^{4}$ This study explores correspondences between social class positions, lifestyles, and tastes of actors in the French society of the 1960s and 1970s. Bourdieu shows that individuals from

3 More than other contemporary sociological approaches - such as, for instance, Niklas Luhman's systemtheory (Luhman 1977, 1997, 2000, 2001) or rational choice theory (Colemann 1992; Elster 1989; Esser 1990; Iannaccone 1990, 1991, 1992, 1994; Lovett 2006; Stark and Finke 2000; Wiesenthal 1987; Young 1997) - Bourdieu's sociology lends itself for the study of Argentinean middle class Pentecostalism since it emphasizes the relationship between social class and practice and thereby allows for exploring potential tensions between class position and religious belonging. Particularly the notion of tastes and styles as class markers contributes to an understanding of Argentinean middle class Pentecostalism, as will be seen later in this study. Bourdieu's sociology has received a wide reception and was applied in manifold ways (for an overview see Sallaz and Zavisca 2007; Swartz and Zolberg 2005). Different strands of Bourdieu reception interpret his sociology in contrasting ways and compete with each other. Hence, the reception of Bourdieu's sociology is very much semantically charged. Using Bourdieu's own terms, the controversies around his sociology appear to constitute a hard-fought social field in which different camps struggle for hegemony. Thus, many scholars read Bourdieu's work in a rather deterministic way: they criticize it for being static and leaving little space for agency and deviations (Bennett et. al. 2010: 27; Gartmann 1991: 422, 438; Jenkins 2002: 149; King 2000: 427-430; Mutch 2003: 389-392; Savage 2003: 540-541; Sewell 1992: 15).

4 See Bourdieu 1979. Bourdieu's main writings concerning the religious field are only of very limited usefulness for studying middle class Pentecostalism in Argentina. His main writings about the religious field are two early articles in which he draws on the sociology of religion of Max Weber (Bourdieu 1971a, 1971b). These articles have been criticized for their focus on the "supply side" of religion and their disregard for the active role of "religious consumers" and the internal diversification process of the religious field (Dianteill 2003: 529, 546; Dillon 2001: 422, 425; Urban 2003: 364-365; Verter 2003a: 151). Yet, the active role of "religious consumers" in form of middle class Pentecostals stands in the center of this study. From this perspective, it appears more fruitful to employ Bourdieu's more developed social theory that he crafted after these two articles (see also Dillon 2001: 426). 
different social positions are inclined to display different cultural tastes and lifestyles. While individuals from the lower class exhibit a taste of the necessary, the middle class tends towards a taste of pretension, and the upper class towards a taste of distinction. Regarding these correspondences between class and taste, Bourdieu argues that cultural taste and lifestyles serve for the distinction and reproduction of social classes. The cultural competence and consumption of individuals - their lifestyles and tastes - act as markers of their class belonging. Cultural tastes and lifestyles are essential characteristics of social class. ${ }^{5}$ Class boundaries are created and reproduced along tastes and lifestyles since they allow for classifying individuals. ${ }^{6}$

Tastes and life styles constitute emblems, markers of class belonging. Dedicating themselves to a specific lifestyle and rejecting the lifestyle of individuals from other social classes, actors classify themselves and (re)produce symbolic class distinctions. ${ }^{7}$ Class-related tastes and lifestyles define what practices and lifestyles are experienced as legitimate in a given class. Thus, actors are supposed to act according to the tastes and styles related to their class position.

The tastes and lifestyles of individuals can be described as manifestations of their habitus. In simple terms, the habitus constitutes an individual's system of interpretative and behavioral dispositions. As such, the habitus is a generative structure that produces the perceptions, thinking, and practices of an individual. The dispositions of the habitus constitute embodied and durable - but not unchangeable - structures that are to a wide extent unconscious and form an embodied, tacit knowledge. The habitus is shaped by the biography of an individual. Actors tend to embody the dispositions of their class environment that they reproduce by showing a class-related taste and lifestyle. ${ }^{8}$ Consequently, individuals with similar social backgrounds and social trajectories are likely to show similar habitus embracing specific tastes and lifestyles, whereas individuals from different class backgrounds will tend to display different tastes and lifestyles. ${ }^{9}$

5 Bourdieu 1979: I-II.

6 Bourdieu states: “(...) étant le produit des conditionnements associés á une classe particulière de conditions d'existence (...) le goût est le principe de tout ce que l'on a, personnes et choses, et tout ce que l'on est pour les autres, de ce par quoi on se classe et par quoi on est classé." (Bourdieu 1979: 59).

7 Bourdieu 1979: 61-64.

8 Bourdieu 1979: 230-232.

9 Bourdieu introduces the concept class habitus in order to grasp this idea. The class habitus translates the objective social life conditions into corresponding tastes and lifestyles. Individual habitus are shaped by class habitus. See, for instance, Bourdieu 1979: 230-232. 
The correspondences between social positions and lifestyles are illustrated in the prominent model of the social space..$^{10}$ The social space is a two dimensional model that allows for representing individuals and their attributes in a space of positions. In this model, Bourdieu relates a space of "objective" social positions to a space of lifestyles. The "objective" positions depend on the amount and composition of "objectified" capital that actors hold. The "objectified capital" in "La Distinction" refers to economic and cultural capital. These two sorts of capital are shown on two scales. The vertical scale indicates the total volume of cultural and economic capital while the horizontal scale exhibits the composition of these two sorts of capital. ${ }^{11}$ In this space of objective positions, actors can be located according to their possession and composition of "objectified" capital. In consequence, the space illustrates the proximity and distance of actors in terms of their "objected" capital. In addition to the space of "objective" positions, the space of lifestyles reveals the proximity and distance of different lifestyles and practices. The social space combines both spaces with each other. In this way, the social space illustrates what types of practice and lifestyles are associated with which objective positions. The model illustrates the proximity and distance of different actors and lifestyles. Individuals that are located in close proximity to each other can be treated as "classes on the paper". ${ }^{2}$ They do not form mobilized classes in a Marxian sense. Instead, they constitute classes of actors located in an "objective" and symbolic proximity, and are, therefore, likely to show similar cultural dispositions and lifestyles.

(...) sets of agents who occupy similar positions and who, being placed in similar conditions and subjected to similar conditionings, have every likelihood of having similar dispositions and interests and therefore of producing similar practices and adopting similar stances.

BOURDIEU 1985b: 725

10 For the social space, see Bourdieu 1979: 109-185, 1984, 1985b, 1994b: 15-29, 1996. In methodological terms there is one important difference between Bourdieu's model of the social space and the model that will be applied in this study. In Bourdieu's "La Distinction" the social space is based on correspondence analysis and the objective positions depend on the following variables: formal education, father's occupation, and income. I will apply a more simple approach to the social space which is based work of the CIRRuS research team at university Bielefeld team (Schäfer et. al. 2016). This space combines the variables household income per capita in Argentinean pesos and education in form of educational degrees.

11 Bourdieu, 1985b: 724.

12

Bourdieu 1985b: 725, 1994b: 26, 54, 1996: 18-19. 
From a vertical perspective - the total volume of capital - the space can be categorized into hierarchical classes: a lower, middle, and upper class hemisphere. Conceiving the model from a horizontal perspective, one can perceive different class fractions in each of these classes. To each of these positions correspond specific tastes and lifestyles. ${ }^{13}$

Combining "objective" positions with tastes and lifestyles, the social space illustrates that the social positioning of individuals is not a simple question of the objective possession of capital but a question of symbolic attributes. Middle class actors get recognized as "middle class actors" if they behave in a middle class way which is different from way of behavior that is attributed to lower classes.

Applying this model to religious practice, one can assume that individuals in different social positions will be inclined towards different religious options. Educated middle class individuals will tend towards types of religious practice that are different from the preferred religious practices of lower classes and allow them to display their middle class position. This is illustrated, for instance, by the critical attitude of the educated Latin American middle class towards popular religion and Pentecostalism. Educated middle class individuals abstain from choosing Pentecostalism and Afrobrazilian religion perceived as typical lower class options. What types of religious practice are regarded as appropriate will depend, among other factors, on the distribution of power in the religious field. This leads us to the concept of social fields.

The concept of social fields describes the horizontal differentiation of modern societies. ${ }^{14}$ On a general level, modern societies can be conceived of as differentiated into relatively autonomous social fields related to specific types of practice and sorts of capital (e.g. political field, academic field, economic field, religious field, field of arts). Depending on the given research focus, fields can be conceptualized as embracing subfields. ${ }^{15}$ This study assumes, for instance, that there is a field of Pentecostalism embedded in the religious field. Fields develop their own logic and rules. Showing different degrees of openness/closeness, fields vary in their autonomy with regard to their environment. ${ }^{16}$

\footnotetext{
13 Bourdieu and Saint Martin 1976: 14-41, Bourdieu 1979: 128-138.

14 For the notion of the social field, see Bourdieu 1979: 249-291, 1993: 107-114, and with a particular focus on the fields of arts, see Bourdieu 1992, 1994b: 61-80.

15 For fields and subfields, see also Fligstein and McAdam 2011.

16 The more developed a field, the more it is likely to operate in a rather in autonomous fashion. See Seibert 2010: 100.
} 
Internally, fields are marked by power struggles. They constitute social arenas where actors compete with each other over the accumulation of specific forms of capital. According to the distribution of capital, actors assume different positions in the field. Similar to the social space, fields are marked by a hierarchical structure. They form hierarchical spaces where different positions are related to different levels of power and legitimacy. The distribution of power shapes the standing and the room for maneuver of actors in the field. Actors who have reached the most dominant positions are able to define the "rules of the game". Holding the highest degree of power, they are able to define the way in which the "game" is played. Actors who engage in the power struggle aim for achieving a dominant position. Struggling for power, they evolve specific styles and employ strategies to improve their position in the field. The strategies and styles engaged in the struggles for recognition are related to the position of actors. Other actors in the field may engage in strategies to delegitimize these strategies and styles. The power struggles of actors in the field can lead to a crisis of dominant structures that may end up in a transformation of the field. In this case, dominant actors, rules and styles change.

For the topic of this study, the religious field and the subfield of Pentecostalism are particularly relevant. ${ }^{17,18}$ Religious actors compete with each other over the religious "market share" and symbolical recognition in the

17 This study employs in some occasions also the metaphor of the religious market in order to underline the competition between religious "suppliers" and the diversity of religious options between which individuals can choose. The use of the market metaphor does not necessarily contradict with the general idea of a religious field. In both competition and diversity is essential.

18 With regard to the religious field, Bourdieu supposes a disintegration process of its boundaries. The boundaries of the religious field fray due to the increasing competition of religious actors with other types of practice related to the physical and mental wellbeing of the modern individual (Bourdieu 1985a). Based on this assumption, Argentinean sociologists often refer to the religious field as a field of healing practices (Algranti 2007b; 2010: 41-45. Algranti and Bordes 2007; Giménez and Esquivel 1996: 63-68; Mallimaci 1996b: 283-284; 2004; 2007: 720; 2008: 85-90; 2009b: 17-19; 2010: 16-17). On this field, different types of medical, esoteric, and religious healing practices compete with each other. Since the focus of this study is on Pentecostals, I will refer to the religious field in a stricter sense and take only actors into account generally considered religious actors. This does not imply that there is no competition between strictly religious and other healing actors. Religious actors are defined as actors whose practice is related to a concept of "transcendence" or "supernatural". Actors who repetitively employ references to some type of "transcendence" can be conceived of as religious actors. For similar definitions of religion that point to the necessity of references to "transcendence", see Krech 2011: 40-43; Luhmann 1977, 2000; Riesebrodt 2007; Schäfer 2009c; Stark and Finke 2000: 89-96. 
religious field. In the course of these struggles, they seek to legitimize themselves and to delegitimize other actors. The model of the religious field employed in this study bases itself upon Seibert's approach to the religious field. ${ }^{19}$ This model illustrates the distribution of power between different religious actors at a given moment of time. ${ }^{20} \mathrm{He}$ defines the field through two types of resources: organizational complexity and credibility. ${ }^{21}$ In this study, I use two slightly different criteria for the design of the religious and the Pentecostal field: (1) the legitimacy of religious actors and (2) the impact of religious actors in the society as defined by their public visibility and the assistance in their religious services. Consequently, religious actors compete over public impact and their recognition as legitimate religious actors. Sketching the positions of religious actors along these categories helps to illustrate the distribution of power between them. In the case of Argentina, the model of the religious space shows that the Catholic Church is the most respected - in other words: the most legitimate - religious actor. Being the most legitimate actor, it attracts established segments of the society. By contrast, religious options that suffer from a low legitimacy but enjoy a high impact among popular segments of the society appeal significantly less to the established segments of the society. This is the case for Argentinean Pentecostalism from which middle and upper class actors seek distinction.

Switching the focus to the field of Pentecostalism, one can sketch a more differentiated picture. On the field of Pentecostalism, there are positions to which a minority of middle class Pentecostals tends. With respect to the dimension of legitimacy, middle class Pentecostals assume with their churches and styles an elevated position in the Argentinean field of Pentecostalism, whereas the majority of lower class congregation suffers from low legitimacy. The positions that middle class Pentecostals assume in the Pentecostal field corresponds to a specific position in the social space - a middle class

19 See Seibert 2010.

20 Seibert 2010: 99.

21 Seibert 2010: 101-109. Credibility does not refer to the religious credibility of actors but to their general social credibility: their recognition as legitimate religious actors. Empirically, the credibility of religious actors refers to the judgments of people about the authenticity of these actors. I will refer with the term legitimacy to this resource. The second resource is the organizational complexity of religious producers. With this criterion Seibert draws on Yinger's seminal differentiation into different types of religious organization. Empirically this resource refers to the numerical distribution between religious experts and ordinary members in the organization, its internal hierarchical stratification, and its level of integration into embracing social structures. Due to the empirical limitations of this study, I will refer simply to the size and visibility of these actors. 
position - which is different from the position of lower class Pentecostals. This shows that the Pentecostal field and the social space intertwine. The position of actors and their styles within a given field will usually correspond to specific lifestyles and positions in the social space.

Seeking distinction from the lower class, middle class actors are inclined to choose religious options that mark a difference with regard to the lower class. Even when choosing "lower class options", such as Pentecostalism, they are likely to evolve techniques to underline their differentness and generate legitimacy. In this way, class boundaries get produced and reproduced in the religious field in the course of symbolic struggles for distinction and legitimacy. These struggles involve practices that stress differentness and attribute and/or withdraw value.

In total, Bourdieu's sociology emphasizes power struggles and the (re)production of class order through the production of symbolical differences. Social positions are created and made visible by symbolic attributes. Due to these attributes actors can be recognized as assuming a certain social position. Hence, symbolic attributes constitute the central feature of class differences. This idea is central for this study and will be further developed by the concept of boundary work and the notion of middle class representations in the following sections.

\section{$2.2 \quad$ Everyday Boundary Work}

Bourdieu's sociology points to the fact that actors draw distinctions in order to mark their social position. Michèle Lamont's concept of boundary work further stresses these struggles for distinction and recognition. Boundary work refers to the efforts of social groups and individuals to create and maintain distinctions vis-à-vis others. ${ }^{22}$ This practice of producing and reproducing distinctions enables for evolving and sustaining social group identities. Boundaries are drawn as "the lines that include some people, groups and things while excluding others" (Lamont 2001: 15341). As such they are employed by social actors to categorize themselves and others. Boundaries can serve as status

22 The term "boundary work" was first time used by Gieryn (1983) to describe the boundary work within science and later overtaken by Lamont (1992) in her seminal study about the French and U.s. American upper middle class. See Lamont 1992; 2001: 15344-15345; Lamont and Fournier 1992; Lamont and Molnár 2002: 171; Pachuki et. al. 2007. For an application of the approach to German's class structure, see Sachweh 2013, to the case of immigration in Europe, Bail 2008 and to musical taste Bryson 1996. For further theoretical developments of the boundary approach, see Wimmer 2008, 2009 . 
markers. They constitute signs that communicate the social position of an actor. For instance, by showing a specific type of behavior, an actor can be classified by middle class peers as a respectable middle class peer or not. ${ }^{23}$

In general terms, one can distinguish between two types of boundaries: symbolic boundaries and objective - or social - boundaries. ${ }^{24}$ In analogy to the "objective" positions of the social space, objective boundaries refer to the "objective" conditions and inequalities that may limit the possibilities of actors. ${ }^{25}$ Lamont and Molnár, referring to objective boundaries as social boundaries, write:

23 See Lamont 1992. In her study about the French and U.s. American upper middle class, Lamont distinguishes between three types of boundaries that upper middle class men employ in order to draw distinctions: socio-economic boundaries, cultural boundaries and moral boundaries. Moral as well as socioeconomic and cultural boundaries can serve as status markers. By placing a high emphasis on moral boundaries, Lamont argues that Bourdieu underrated morality as a resource for boundary work (Lamont 1992: 184-185). For the American and French upper middle class Lamont reports moral boundaries to be essential. Skeggs (2005) also refers to moral boundaries by describing the moral boundary work of the middle class in Britain.

24 I subsequently use the term "objective boundaries". The term "objective" is preferred over the term "social" for two reasons. First, the term "social" is confusing when referring to these characteristics since "social" can refer in a sociological study also to many other characteristics. Second, the term "objective" gives consideration to the fact that these characteristics are generally regarded by actors and sociologists as the attributes that define the social position of a given individual in an "objective" or "objectified" manner (e.g. in form of the economic income and educational level of the individual).

25 It is often difficult to differentiate empirically between objective and merely symbolic boundaries since objective boundaries are symbolic boundaries that have turned into structural arrangements, into objective conditions of existence. The "objective" boundaries the social structure - of a society are the result of the distribution of particular recourses (forms of capital). These resources are not valuable by nature. They obtain their value by the society in which they are placed. Their objectivity appears to be related to the fact that they constitute resources which are acknowledged by the whole of the society, embracing individuals from all social positions, whereas other sorts of resources - symbolic boundaries may be only acknowledged by certain groups or classes. The general acknowledgment of these sorts of resources (boundaries) - as well as their convertibility - objectifies them: they become objective criteria for the categorization and hierarchization of individuals. Sociologists make use of these criteria in order to attribute individuals to classes and generate a picture of the social structure of a society. Symbolic boundaries and objective boundaries interact strongly with each other. Hence, the possession of specific symbolic characteristics - such as particular lifestyle - may shape the objective life conditions and vice versa. Symbolic boundaries do not only mark, but may also enforce and maintain objective boundaries. See Bourdieu 1979; Lamont and Molnár 2002: 167-169. 
Social boundaries are objectified forms of social differences manifested in unequal access to and unequal distribution of resources (material and nonmaterial) and social opportunities.

LAMONT and MOLNÁR 2002: 168

Drawing on Bourdieu's concept of the social space, objective boundaries can be interpreted as forms of "objectified" capital. In the majority of modern societies, the most salient forms of objectified capital are cultural capital (education), economic capital (income), and additionally the job occupation of actors. ${ }^{26}$ Individuals have to hold a specific amount of economic and cultural capital in relation to other individuals of a given society to be "objectively" classified by other actors as middle class individuals. ${ }^{27}$

Symbolic boundaries, by contrast, refer to the symbolic attributes - such as appearances, tastes, (moral) attitudes, and lifestyles - of actors. Individuals draw symbolic boundaries by showing distinctive tastes and lifestyles. Displaying these symbolic characteristics, they portray their belonging to a "class of individuals" and their differentness from other "classes of individuals", which are experienced as less valuable. ${ }^{28}$

Both - objective and symbolic boundaries - are employed in boundary work to mark social belonging and (re)produce the distinguishing lines between classes of actors. ${ }^{29}$ Objective and symbolic class belonging are usually expected to go along with each other. Individuals that are "objectively" located in a middle class position - due to their level for school education and their occupation - are expected to behave like middle class individuals. They are expected to perform their social position in everyday boundary work.

The practice of drawing distinctions in everyday life is defined in this study as everyday boundary work. Individuals draw boundaries in their daily life. These boundaries enable them to mark their belonging to a "class of

26 See Bourdieu 1996: 13; Kraus et. Al 2011: 246.

27 While actors draw symbolic boundaries in their everyday practices, scholars usually define objective boundaries in advance. Studying social classes, scholars already claim to know what the "lower class" or "middle class" is, irrespectively of how actors define social classes. Yet, when taking the cultural (symbolic) approach to social class seriously, scholars have to take into account that not their definitions but the class definitions of actors frame their everyday boundary work. See Visacovsky 2008: 20-23.

28 Thus, McCloud states: "Class concerns boundaries, those distinctions that we make between ourselves and others." (McCloud 2007a: 2).

29 The class-related lifestyles, tastes and habitus that Bourdieu describes in "Distinction" can be interpreted as symbolic boundaries that allow classifying individuals. See Lamont and Molnár 2002: 172. 
individuals" and to generate respectability in the presence of their peers. Everyday boundary work usually implies the displaying of particular tastes and styles. ${ }^{30}$ Taste refers to the communication of preferences that may imply judgments about the quality and/or legitimacy of other individuals, groups, things, or attributes. Individuals can, for instance, express disdain for a specific type of practice in front of their peers. In this way they draw a symbolic boundary between themselves and the practice, as well as the characteristics and people that are associated with the practice. Style refers to the display of specific attributes in everyday practice such as dressing, moving, or speaking in a specific way.

The advantage of boundary work is that it reveals on a micro level how individuals draw boundaries in their daily lives. It refers to the daily practice of drawing boundaries in which actors engage to mark their differentness from other people and their attributes and to generate respectability among peers.

These boundaries are not created in a symbolic vacuum. They are based on the symbolic resources - discourses, values, etc. - within a social class. ${ }^{31}$ Thus, middle class actors are likely to employ established boundaries in their everyday boundary work. They make use of attributes that are generally recognized by their peers as valuable and appropriate. The concept of middle class representations, which will be described in the following section, refers to this pool of established middle class boundaries.

\subsection{Middle Class Representations}

A class-related pool of established boundaries frames the everyday boundary work of actors. Actors can employ boundaries from this pool in order to mark their class belonging and to pursue the recognition of their class peers. This pool of established boundaries is termed "class representations". ${ }^{32}$ Class

30 Tastes and styles intertwine. The way in which actors speak and move can imply judgments of taste in particular social situations. Similarly, the way in which individuals communicate their preferences is a question of style. Moreover, individuals that express a particular taste are generally expected to implement this taste in their style and vice versa. Empirically there may be, of course, differences between the communicated tastes and practices of actors. For instance, despite expressing disdain for a specific practice in some situations, the same individual can be dedicated in other situations to the given practice.

$31 \quad$ See Lamont 1992: 7 , 11.

32 The notion of social representations is borrowed from Moscovici $(1976 ; 1988 ; 1998)$. In the words of Moscovici, social representations correspond to "a certain recurrent and 
representations refer to inter-subjectively shared class imaginaries consisting of class-related boundaries that imply standards of appropriate behavior. ${ }^{33}$ Due to the focus of the study, there will be an emphasis on the class representations of the middle class. Middle class representations can be interpreted as an accumulation and combination of symbolic boundaries on which middle class actors widely agree. ${ }^{34}$ Together they form an ideal-typical image - a social imaginary - of the middle class that defines the characteristics conceived of as typical middle class characteristics. These representations

comprehensive model of images, beliefs and symbolic behaviours. (...) representations (...) order around a theme (mental illness are contagious, people are what they eat) a series of propositions which enable things or persons to be classified, their character described, their feelings and actions to be explained, and so on." (Moscovici 1998: 243) Based on the notion of social representations a wide variety of research has been conducted, especially in social psychology, and has contributed to develop the concept in different directions (Bauer and Gaskell 1999). I apply the notion in a specific way and refer particularly to the social representations of the middle class which are produced and reproduced in "middle class" communications and practices. The concept of class representations is employed in a likewise manner by Skeggs $(1997,2004)$. In „Ce que parler veut dire" Bourdieu (1982) employs also the term "representations". In some parts of this work, he employs representations as group-related schemes of classification ("classement") which enable actors to classify other actors, things, and practices (Bourdieu 1982: 147). These classifications are subject to power struggles. Individual actors and groups engage in power struggles to impose their representations as "objective" representations (Bourdieu 1982: 136-142). Their success depends on their ability to represent with their representations the group in which they seek to establish these representations (Bourdieu 1982:101, 152). This study suggests that middle class representations impose classifications (representations) on those who move within middle class environments. These classifications classify particular practices, actors, things, and concepts as appropriate and other practices, actors, things, and concepts as inappropriate.

33 For imaginaries, see Guano 2004, Reay 2007b, Strauss 2006. In Bourdieu 's terminology "doxa" reflects some of the characteristics of social class representations. It is the sense of the appropriate and of one's place (Bourdieu 1979: 549; 1984: 8).

34 If the belief in specific boundaries is widely shared among actors they become part of the class representations. Barth, for instance, writes with regard to ethnic groups: "The identification of another person as a fellow member of an ethnic group implies a sharing of criteria for evaluation and judgment. It thus entails the assumption that the two are fundamentally 'playing the same game' (...)." (Barth 1969/70: 15) Barth stresses particularly the process of boundary construction and maintenance. He promotes a focus "on the boundary and the processes of recruitment not on the cultural stuff that the boundary encloses." (Barth 1994: 12) The present study assumes that content is a basic element of "boundary work". Contents have to be pushed forward in order to draw and maintain boundaries between groups. 
embrace an understanding of what types of behavior are regarded as appropriate in middle class environments and what types of behavior not. ${ }^{35}$

The pool of established boundaries constitutes at the same time a resource for and a product of the daily boundary work of actors. Class representations develop over time. They emerge as a product of historical institutionalization processes. ${ }^{36}$ Boundaries that become constantly engaged in the everyday boundary work of middle class actors assume a rule-like status over time. Progressively assuming a binding character, individuals are increasingly expected to orientate their boundary work upon them. Class representations are related to the routinization of practice. ${ }^{37}$ They reflect a routinized way of drawing class distinctions. ${ }^{38}$

Middle class representations constitute social norms. As such, they provide criteria according to which social behavior can be assessed and classified. Middle class actors are likely to evaluate their own behavior and that of others according to these criteria. Whenever they publicly fail to follow these criteria

35 These boundaries are produced and reproduced in everyday interaction and mass media communication but also by sociologists who contribute to class imaginaries by allocating individuals into groups that tend to show particular types of behavior (Lahire 2001).

36 From the perspective of new institutionalism (DiMaggio and Powell 1991; Hall and Taylor 1996; March and Olsen 1989, 2009; Scott 2008; Thelen 1999), middle class representations are institutions. Institutions are - in a wider sense - rules which structure interactions by providing normative orientation. They consist of "durable social structures made up of symbolic elements" (Scott 2008: 48). These structures "arise in interaction, and they are preserved and modified by human behavior." (Scott 2008: 49) Being the product of a constant reproduction in daily practices, institutions are relatively stable and tend to change only slowly (Scott 2008: 48-49). Being a social institution, middle class representations fulfill two functions. They assume a regulative function for social behavior and they provide recourses for daily interaction (Scott 2008: 50).

37 Reckwitz 2002.

38 This routinization of class practice could be also described by the concept of class habitus (Bourdieu 1979: 230-232). The theoretical approach outlined here is based on a specific interpretation of this class habitus. In this reading, the class habitus is conceived of as an institution, a pool of established boundaries that assumes a rule-like character for the daily boundary work of actors. This class habitus does not necessarily refer to the way in which individuals act but rather to the expectations that are related to their behavior. Since the class habitus is usually not understood as merely forming a social norm, the notion of middle class representations was chosen to avoid misunderstandings. The present interpretation of the class habitus could be perhaps described as a new-institutionalist approach to the class habitus. For an overview of new-institutionalism and its different strands, see Hall and Taylor 1996, and Thelen 1999. 
they may show regret and try to camouflage their "wrongdoing". ${ }^{39}$ Nevertheless, middle class representations do not define exactly how an actor has to behave: they provide criteria for appropriate behavior and set limits defining the boundaries of appropriate practice. Within these limits a wide variety of practices and attributes is conceived of - to different degrees - as appropriate. ${ }^{40}$ Hence, middle class individuals can combine practices from a wide spectrum to design their individuality without necessarily crossing the limits of appropriate behavior. Yet, their behavior can and will be evaluated as more or less appropriate. Being committed to less appropriate practices can affect the appraisal that other middle class individuals have for an actor and create tension. ${ }^{41}$

Middle class representations allow for classifying individuals and their practices by defining what type of behavior and person is respectable and what type of behavior and person is not. From the viewpoint of the middle class, it is particularly the lower class and its practices that are perceived as less respectable and appear as deficient. ${ }^{42}$ Rejecting the lower class is a way of generating value, as Skeggs points out. ${ }^{43}$

39 See Lahire 2001: 78; 2004/2006: 627-636; 2005 .

40 See, for instance, Bennett et. al. 2010: $25^{2}$.

41 See Scott 2008: 55. Frederik Barth states with reference to ethnic groups: "Since belonging to an ethnic group implies being a certain kind of person, having that basic identity, it also implies a claim to be judged oneself, by those standards that are relevant to that identity." (Barth 1969/70: 14).

42 See Skeggs 1997: 167. Skeggs states: “(...) representations are a key site in this class struggle; they are where symbolic violence occurs. Who would want to be seen working class? (Possibly only academics are left.) Within the field of cultural criticism working class people have come to be seen as bearing the elemental simplicity of class consciousness and little more." (Skeggs 1997: 95) Thus, lower class culture in Great Britain is perceived as deficient (Reay 1998: 264, 267; 2005a: 921; Skeggs 2004: 79-118; 2005). In "Class, Self, Culture" Skeggs writes with reference to the case of Great Britain: "The working-classes are being spoken of in many ways: as underclass, as white blockage to modernity and global prosperity, as irresponsible selves to blame for structural inequality, as passive nonmarket competitors, as lacking in agency and culture, whilst the middle-classes are represented as at the vanguard of the modern, as a national identity and a cultural resource. In this symbolic identification and evaluation we see class divisions being made. The rhetorical positioning of the working-class is a powerful formulation, presented as literally use-less, a group as inept as they are dysfunctional. (...) They are represented as having nothing to offer; their culture is not worth having; they only represent a burden." (Skeggs 2004: 94).

43 Further, Skeggs supposes that the need to draw and maintain boundaries indicates the fragility of the middle class: "The proliferation and reproduction of classed representations 
Attributing negative value to the working class is a mechanism for attributing value to the middle class self (such as making oneself tasteful through judging others to be tasteless). (...) Any judgment of the working-class as negative (waste, excess, vulgar, unmodern, authentic etc.) is an attempt of the middle class to accrue value.

SKEGGS 2004: 118

Drawing distinctions in opposition to the lower class contributes to the constitution of a valuable middle class self. This is also evident in the case of Argentina. In Argentina, which is shaped by a strong middle class discourse, the middle class is imagined as white, European, well-educated, tidy, rational (vs. superstitious) and sober (vs. emotional). These representations are based on boundaries that are established as in opposition to the lower class often imagined as untidy, superstitious, uneducated etc. ${ }^{44}$ The vigor of class representations depends on their reproduction in everyday boundary work. In order to maintain the imaginary of the middle class, the established boundaries have to be reproduced and portrayed. Goffman underlines this need to reproduce the class representations:

A status, a position, a social place is not a material thing, to be possessed and then displayed; it is a pattern of appropriate conduct, coherent, embellished, and well articulated. Performed with ease or clumsiness, awareness or not, guile or good faith, it is none the less something that must be enacted and portrayed, something that must be realized.

GOFFMAN 1959: 75

Class boundaries have to be cultivated and nourished. Boundary work consists not only of creating boundaries, but also in maintaining them: middle class individuals have to behave according to the class representations or at least to

over such a long period of time demonstrates the understated ubiquity of class, showing how it is continually referenced, even when not directly spoken. Proliferation and repetition, also point to the fragility of the authority of the middle class. If they were secure, difference would not be continually be drawn, values established, legitimated and institutionalized." (Skeggs 2004: 117).

Interestingly, also Argentinean sociologist Gino Germani refers to social class representations which he calls the "psycho-social criterion" of class belonging. He distinguishes the psycho-social criterion from the objective criteria of the class belonging - namely income, education, and occupation - and describes them as the typical attitudes of the middle class as a system of values (Germani 1950: 5) and as collective representation (Germani 1981:110-111). 
create the impression that they do so. ${ }^{45}$ Consequently, everyday boundary work contributes to the reproduction of the class representations by reproducing the "appropriate" and the distinction from the "inappropriate".46

In order to maintain symbolic class representations, middle class actors are expected to act according to their class representations and therefore to behave differently from the attributes that are associated to the lower class. ${ }^{47}$ Thus, Argentinean middle class individuals are expected by their peers to dress in a tidy way and address themselves in an educated manner to others. By acting according to the middle class representations they do not only mark their middle class position, but reproduce also the established middle class boundaries and maintain them in vigor. In total, the concept of boundary work underlines that the formation of classes is about the (re)production of symbolic hierarchies in everyday practice. ${ }^{48}$

\subsection{Relating Boundary Work and Class Representations to the Social Space}

The previous thoughts can be related to the concept of the social space. Applying the model of the social space, correspondences between class representations and "objective" social positions can be supposed. Middle class

45 The established class boundaries must be reproduced in practices and discourses. Middle class representations are not only (re)produced in everyday interactions between individuals but also by the mass-media which transmits ideal-typical images of the middle class.

46 Nevertheless, class representations are alterable. They evolve over time and can be subject to significant changes. New boundaries may be drawn, while others evaporate leading to a modification of class representations. Previously unaccepted practices may become tolerated while once accepted practices can convert into inappropriate practices. The cultural ascriptions of a group may change without necessarily undermining its boundaries, as Frederik Barth (1969/1970) has argued with regard to ethnic group boundaries.

47 Consequently, the empirical differences in the practices of social classes may not only be due to the reproduction of embodied social structures but also due to a calculated adaptation of visible behavior: actors adapt their behavior to what they think is appropriate with regard to the social class they represent and the sort of situation (formal/informal, public/private) in which they are. As already stated above, this approach does not neglect the reality of socialization and internalization of social structure, but it is cautious with respect to the degree and detectability of embodiment of social structure. Concerning the adaptation of human behavior to standards of appropriateness in mind March and Olsen (2009) speak of a "logic of appropriateness".

48 Reay 1998; 2005a: 924; Skeggs 2004; Savage 2003. 
representations are likely to show a normative pressure on the behavior of actors located in objective social positions usually associated with the middle class. Facing normative pressure to act according to the middle class representations, actors will be inclined towards drawing boundaries in their daily boundary work that conform to the representations of the middle class.

Yet, not only individuals generally perceived as being situated in a middle class position may relate their daily boundary work to the representations of the middle class. Also lower class actors with middle class aspirations may orientate their boundary work toward some of the established boundaries of the middle class representations. Consequently, the approach does not suggest that there are exclusive correspondences between the normative orientation on middle class representations and the positions that are usually regarded as fitting "objectively" to the middle class. ${ }^{49}$

Moreover, the everyday boundary work of individuals will not only be based on class-related boundaries. Besides class representations, daily boundary work will be based, for instance, on gender representations and representations that define what is appropriate in particular age groups. ${ }^{50}$

In total, the model supposes that in some positions there exists a normative pressure to act according to the middle class representations. When assuming

49 Considering the horizontal differentiation of the social space, the space entails not only classes, but also class fractions. These class fractions stick to specific variations of their class representations (Bourdieu and Saint Martin 1976: 14-41, Bourdieu 1979: 128-138.). Hence, different middle class fractions are likely to adhere to specific variations of the middle class representations that emphasize different boundaries. These variations will express themselves in different forms of daily boundary work. Despite these variations among middle class fractions, there will be a general agreement on many middle class attributes. The agreement on these attributes helps to draw and stabilize the fundamental boundaries in opposition to the lower class. Due to the lack of research about internal differences in Argentina's middle class and the limitations of the empirical sample, this study only stresses the general middle class representations.

50 Besides class representations there will be other group related representations that shape the behavior of individuals. Thus, there will be representations related to gender and ethnicity as well as representations for specific sub-cultures such as, for instance, Heavy Metal fans. These types of representations may also have an impact on religious practice. Thus, in addition to social class other factors are also likely to play an important role for shaping religious practice (McCloud 2007a: 14-15, 29-30; 2007b 845; see for ethnicity Althoff 2006). Different representations may overlap and conflict with each other leading to contradicting expectations of behavior. Furthermore, actors may also draw boundaries to underline their individuality and seek distinction from others of their social class. However, pursuing at the same time the recognition of their class peers, they may combine their individual with a class-related boundary work. 
positions that are generally conceived of as middle class positions, actors are likely to act in social environments framed by the expectation to behave according to the middle class representations.

Based on these theoretical considerations, the way in which the term "middle class" is employed in this study can be outlined in following way. Middle class actors are defined by taking the "objective" and symbolic attributes of actors into account. First, middle class actors are actors "objectively" situated in the middle class. This means they hold a certain amount of "objectified" capital in form of education and income that differentiates them "objectively" from the lower class and the upper class. Second, when moving in middle class contexts, middle class actors usually relate their everyday practice to the middle class representations. This does not imply that they strictly follow the middle class representations in their daily practice. However, in public situations with middle class peers present, they likely employ the middle class representations as a normative standard for their public behavior. In these middle class contexts, they generally seek to appear as appropriate middle class actors. In order to portray themselves as appropriate middle class actors, they may employ established middle class boundaries by displaying "middle class" tastes and styles.

\subsection{Towards Religious Non-conformance}

With respect to the religious field, middle class representations are likely to infer particular views on different types of religious practice. Religious options will be regarded to different degrees as appropriate and legitimate. For instance, religious practices that imply emotional outbursts or shouting and crying in public may be perceived as inappropriate. ${ }^{51}$ Also, specific faith communities judged negatively by the middle class may not be regarded as appropriate religious options. Particularly the imaginary of the "sect" illustrates the risk of crossing boundaries when choosing an "inappropriate" religious option. Thus, Corten describes the sect in opposition to the middle class: the sect is the place where practices that are perceived as unacceptable by the middle class may become manifest. ${ }^{52}$ As Nathalie Luca points out, the membership in a religious

51 For instance, Chaves indicates for the United States that middle class congregations tend to show more formal styles of worship whereas worships of lower class congregations are inclined towards a more spontaneous and less formal styles (Chaves 2004: 136).

$5^{2}$ "La secte est l'« ailleurs » où le «non-de-classe-moyenne » peut se présenter avec son langage, avec ses émotions, avec son imagination." (Corten 1995: 248). 
group that is perceived as unacceptable, as a "sect", may be experienced as a rupture with the "pacte citoyen". ${ }^{33}$ By belonging to an "unacceptable" religious group or conducting unacceptable religious practices, the individual may cross the border of respectable citizenship and runs the risk of becoming an inappropriate other in the eyes of his/her peers. ${ }^{54}$ Middle class actors risk becoming excluded from the imagined circle of the respectable middle class. Therefore, they will rather avoid these groups.

This is the case with Pentecostalism in Argentina. Here, the educated middle class shows a critical attitude towards Pentecostalism. Embracing characteristics - such as exorcisms, prosperity gospel, faith healing, emotional outbursts, etc. - perceived as inappropriate, and being regarded as a religion of the ignorant and poor, Pentecostalism does not fit well with the representations of the educated middle class. Therefore, middle class actors tend to avoid Pentecostalism. Instead, they gravitate towards religious practices that are perceived as more appropriate such as, for instance, Catholicism.

Nevertheless, the negative attributes associated with Pentecostalism do not prevent some middle class individuals to affiliate with the movement. Although Pentecostalism does not fit well with the representations of Argentina's educated middle class, there is a group of highly educated middle class individuals in Argentina that shows an affinity for Pentecostalism. Affiliating with a religious movement that involves "inappropriate" characteristics and tends to be perceived as a lower class religion, they deviate to some extent from the middle class representations.

For this reason, this study has to take non-conformance with class order into account. One sociologist who addresses the topic of non-conformance is Bernard Lahire. The work of Lahire reveals that middle class actors frequently deviate in their cultural practices from what is considered legitimate and appropriate. ${ }^{55}$ However, when performing non-conforming practices, middle

53 Luca 2009: 238. For the public discourses about "sects" and the often tense relationship between citizenship and sect membership which public discourses create, see Luca 2002; 2004a; 2008b; 2009; 2010.

54 See Lamine 2009, Skeggs 2004: 94; 2005: 977.

55 Non-conformance with class order appears to be a ubiquitous phenomenon. Lahire 2001; 2004/2006; 2005; 2008. Also Schäfer (2002: 286-287; 2005: 275-276) points to the presence of deviations. The presence of non-conforming behavior raises the question of why individuals show non-conforming tendencies. Forming its own strand of sociology, the study of deviation has generated a wide array of approaches that describe and explain nonconforming behavior (Clinard and Meier 2008; Lamnek 2007, 2008). Immersing into this academic debate is beyond the scope of this study. In general terms, inappropriate tendencies can be the product of genetic predispositions, psychological factors and/or social 
class actors often express regret and shame, or engage in strategies to disguise the inappropriateness of their actions. This applies also to Argentina's middle class Pentecostals who have an affinity for Pentecostalism and some of its "inappropriate" practices such as speaking in tongues. These "inappropriate" religious affinities can arise from an early contact with the universe of popular religion, as will be shown below.

Middle class Argentineans, dedicating themselves to "lower class options" such as Pentecostalism, overstep to some extent the boundaries of the educated middle class. A mismatch between their religious belonging and their symbolic class belonging emerges. Middle class actors who openly cross the established symbolic class boundaries manipulate the representations of the middle class. Therefore, their behavior may be sanctioned. They risk being stigmatized and being considered as less worthy than other class members. In extreme cases peers, may even exclude them from the imagined circle of the "respectable middle class". ${ }^{6}$

Many of the middle class Pentecostals I interviewed had suffered from different types of tension due to their religious belonging. They were, for instance, discriminated against by work colleagues, lost contact to their friends after their conversion, suffered rejection from relatives, and were described by middle class peers as lunatic. The non-conformance of middle class Pentecostals

influences (Clinard and Meier 2008: 42-65). For instance, Bradshaw and Ellison (2008) point to the influence of genetic factors on religious practice. Due to the sociological character of this study, the influence of genetic and psychological predispositions on the religious affinities of middle class Pentecostals cannot be explored here. A sociologically more accessible factor is social influence. Approaches that fit to the findings of the present study are proposed by Lahire and Schäfer's notion of the habitus as a complex network of dispositions (Lahire 2003, 2004/2006, 2010; Schäfer 2005, 2015). These approaches suggest that individuals become socialized and participate in various social environments that may sometimes imply conflicting social standards. Thess approach to non-conformance can be related to the sub-culture and socialization approaches of deviant behavior. Sub-culture approaches underline the existence of various groups and cultural spheres in which different, sometimes contradicting, values are valid (Clinard and Meier 2008: 12-15; Lamnek 2007: 147-189, 2008: 80-87). Socialization approaches to deviance point out that non-conforming behavior is often a product of socialization: "deviant" norms, values, affinities have been learned by actors in the course of their socialization (Clinard and Meier 2008: 43-49; 99-104; Lamnek 2007: 190-222). Thus, non-conforming behavior is learned in specific sub-cultures or groups. The learned behavior stands in conflict to the norms of the social environment in which the behavior is labeled as deviant.

$5^{6}$ Discrepant behavior will be avoided and may be sanctioned. See, for instance, Barth 1969/70: 18; 1994: 22-23. 
raises the question of how they deal with the inappropriateness of their religious practice.

\subsection{Boundary Work as a Way of Dealing with Non-Conformance}

Individuals that constantly cross class boundaries likely develop techniques to deal with the tension between their non-conforming practice and the class representations. Theoretically, they can hide these practices from the eyes of class peers and dedicate themselves to these practices only in the intimacy of their private sphere. ${ }^{57}$ This, however, is not always feasible for middle class Pentecostals since Pentecostals are required to stick to their religious beliefs. They are not permitted to deny their religious identity in public and are supposed to practice their faith in a congregation.

Instead, middle class Pentecostals dedicate themselves to symbolic boundary work in order dissolve the tensions between their class belonging and their religious belonging. ${ }^{58}$ This boundary work could perhaps be labeled "second order boundary work" since it is conducted in order re-establish the boundaries that were crossed in the first place. To perform this "second order" boundary work middle class Pentecostals employ distinctive religious tastes and styles in Pentecostalism.

Religious tastes refer to the preferences that actors communicate concerning the practice of religion. Actors display likes and dislikes regarding the way in which religion is practiced. By expressing a specific taste they can draw boundaries vis-à-vis particular characteristics of religious practice. For instance, middle class Pentecostals may communicate that they dislike emotional practices in church services. Manifesting this dislike, they draw a boundary in opposition to an emotional type of Pentecostalism. Religious style, in contrast, refers to the way in which religion is practiced. In this study, I will refer with the term predominantly to the religious style of churches. The religious style of a church embraces a variety of characteristics: its symbolic recognition, the form in which its church services are conducted as well as the configuration of its physical infrastructure and organization. One method to identify the boundary work of middle class Pentecostals will be the empirical comparison of the tastes and styles of middle and lower class Pentecostals.

57 See, for instance, Clinard and Meier 2008: 52-53; Goffman 1959; Lahire 2004/2006: 627-632.

$5^{8}$ Similarly to the British working-class in the studies of Skeggs $(1997,2004)$, middle class Pentecostals develop strategies to generate - despite their inappropriateness - respectability. 
Religious tastes and styles are engaged in the boundary work of Argentina's middle class Pentecostals. Middle class Pentecostals draw boundaries in opposition to the "inappropriate" characteristics of Pentecostalism by displaying distinctive tastes and styles of Pentecostalism. These tastes and styles become, for instance, visible in specific ways of organizing their churches, carrying out church services, performing spiritual practices, and speaking about other Pentecostals. Displaying these distinctive tastes and styles permits middle class Pentecostals underlining their differentness from other Pentecostals.

The boundary work of middle class Pentecostals is based on preexisting resources. They lend established boundaries from the middle class representations. Middle class Pentecostals employ characteristics that are conceived of as appropriate - such as, for instance, the ideal of education - and attribute them to Pentecostalism. At the same time, characteristics that may be perceived by non-Pentecostal middle class peers as inappropriate are banned from the public sphere of the church service and transferred into the private sphere. Middle class Pentecostals appear to separate between the private and public practice of Pentecostalism. This distinction can be grasped by Goffman's concept of impression management that differentiates between a front region and a back region. On the front region, individuals tend to disguise inappropriate tendencies and try to perform a play that corresponds to the middle class representations. In the back region, by contrast, inappropriate tendencies that do not fit well to the standards of appropriate behavior can become manifest. ${ }^{59}$ Inappropriate practices such as speaking in tongues and exorcisms are more likely to be carried out in private contexts. Church services, in contrast, are experienced as a public sphere since they are also accessible for non-Pentecostal class peers. For this reason, the church service forms a highly controlled social sphere from which the inappropriate aspects of Pentecostalism - such strong spiritual practices - have to be withdrawn. Attributing appropriate, middle class characteristics to Pentecostalism and banning inappropriate, "lower class" characteristics from the public practice of Pentecostalism, middle class Pentecostals engage in crafting a Pentecostalism that appears as more appropriate from the viewpoint of their class representations.

When being dedicated to an inappropriate practice, boundary work consists of drawing distinctions in opposition the inappropriate characteristics of this practice and thereby creating an appearance of appropriateness. This boundary work serves two purposes. First, on the macro-level of the class representations, it allows to maintain class representations, since the established class boundaries are reproduced by performing the practice in a more 
appropriate way. Second, on the micro-level of the individual, it enables individuals to deal with their inappropriateness and to negotiate the legitimacy of their practice. Middle class Pentecostals renegotiate their symbolic class belonging and the appropriateness of their religious practice by drawing boundaries as in opposition to the inappropriate characteristics of Pentecostalism. However, the negotiation function of everyday boundary work does not imply that the inappropriateness and the social tensions related to the non-conformance fully disappear. Some inappropriate characteristics and misfits may persist. But even so, boundary work makes allowance for partly disguising inappropriateness, renegotiating value, and reducing social tensions.

\subsection{Summary}

The aim of this chapter was to advance a theoretical approach for studying middle class Pentecostalism in Argentina. Using sociological theory as a tool kit to explore social phenomena, the theoretical approach was developed in a dialogue with the empirical findings. Therefore, the theoretical approach started from the sociology of Pierre Bourdieu and extended it by adding the notions of boundary work and middle class representations. The concepts of boundary work and middle class representations, closely linked to Bourdieu's sociology, allow for emphasizing two important characteristics of Argentinean middle class Pentecostalism: the non-conformance with class standards and the negotiation of this non-conformance. The distinction between established class boundaries (class representations) and the everyday practice of drawing class boundaries provides a helpful theoretical device to explore these characteristics.

Everyday boundary work is related to the daily struggle for recognition and refers to the daily practice of drawing symbolic boundaries. Individuals draw symbolic boundaries in order to generate recognition and appear as respectable citizens in the glances of their peers. By displaying specific attributes in form of tastes and styles, individuals portray themselves as forming part of a class of individuals which is different from other classes of individuals which are perceived as less valuable, legitimate, respectable, or just as different. Everyday boundary work does not take place in a symbolic void. It is usually based on institutionalized boundaries that have become established over time. Thus, the boundary work of middle class actors is likely to be framed by established middle class boundaries. These established middle class boundaries are labeled as "middle class representations" in this study. They constitute a class 
imaginary that does not only provide symbolic resources for everyday boundary work but that exercises also normative pressure on individuals' everyday practice. Nevertheless being a normative and ideal-typical representation, individuals do not necessarily follow its normative standards in their everyday practice.

The theoretical approach of this study supposes that everyday practice is framed but not determined by symbolic class representations. Individuals may deviate in their practice from what is regarded as appropriate by class peers. Having non-conforming affinities, individuals may dedicate themselves to inappropriate practices. "Inappropriateness" is a ubiquitous phenomenon, as Lahire has pointed out. When facing the risk of being depreciated for their inappropriate tendencies, actors can renegotiate the appropriateness of these tendencies in their everyday boundary work. By displaying distinctive tastes and styles that draw boundaries in opposition to the inappropriate characteristics of the given practice, individuals can portray their practice in a more appropriate light. Hence, everyday boundary work consists in creative maneuvers to disguise one's inappropriate tendencies. Drawing boundaries as in opposition to the inappropriate is a creative effort that goes beyond a rigid reproduction of middle class representations.

This study suggests that middle class Pentecostals renegotiate the appropriateness of their religious practice through boundary work. This boundary work consists in displaying distinctive tastes and styles of Pentecostalism according to which they present themselves as less emotional, less superstitious, more ordered and educated, in other words: more middle class than other Pentecostals. 